\title{
Creation of Consistent Burn Wounds: A Rat Model
}

\author{
Elijah Zhengyang $\mathrm{Cai}^{1}$, Chuan Han $\mathrm{Ang}^{2}$, Ashvin Raju' ${ }^{2}$, Kong Bing Tan ${ }^{2,3}$, \\ Eileen Chor Hoong Hing ${ }^{2,4}$, Yihua Loo ${ }^{5}$, Yong Chiat Wong ${ }^{6}$, Hanjing Lee ${ }^{4}$, Jane Lim ${ }^{2,4}$, \\ Shabbir M Moochhala ${ }^{6}$, Charlotte AE Hauser ${ }^{5}$, Thiam Chye Lim ${ }^{2,4}$ \\ ${ }^{1}$ Department of Surgery, National University Health System, Singapore; ${ }^{2}$ Department of Surgery, Yong Loo Lin School of Medicine, Natioanl \\ University of Singapore, Singapore; ${ }^{3}$ Department of Pathology, National University Health System, Singapore; ${ }^{4}$ Division of Plastic, \\ Reconstructive and Aesthetic Surgery, Department of Surgery, National University Health System, Singapore; Institute of Bioengineering and \\ Nanotechnology, Agency of Science, Technology and Research, Singapore; ${ }^{6}$ Defence Medical and Environmental Research Institute, DSO \\ National Laboratories, Singapore
}

Background Burn infliction techniques are poorly described in rat models. An accurate study can only be achieved with wounds that are uniform in size and depth. We describe a simple reproducible method for creating consistent burn wounds in rats.

Methods Ten male Sprague-Dawley rats were anesthetized and dorsum shaved. A $100 \mathrm{~g}$ cylindrical stainless-steel rod ( $1 \mathrm{~cm}$ diameter) was heated to $100^{\circ} \mathrm{C}$ in boiling water. Temperature was monitored using a thermocouple. We performed two consecutive toe-pinch tests on different limbs to assess the depth of sedation. Burn infliction was limited to the loin. The skin was pulled upwards, away from the underlying viscera, creating a flat surface. The rod rested on its own weight for 5, 10, and 20 seconds at three different sites on each rat. Wounds were evaluated for size, morphology and depth.

Results Average wound size was $0.9957 \mathrm{~cm}^{2}$ (standard deviation [SD] 0.1845) $(\mathrm{n}=30)$. Wounds created with duration of 5 seconds were pale, with an indistinct margin of erythema. Wounds of 10 and 20 seconds were well-defined, uniformly brown with a rim of erythema. Average depths of tissue damage were $1.30 \mathrm{~mm}$ (SD 0.424), $2.35 \mathrm{~mm}$ (SD 0.071), and 2.60 $\mathrm{mm}$ (SD 0.283) for duration of 5, 10, 20 seconds respectively. Burn duration of 5 seconds resulted in full-thickness damage. Burn duration of 10 seconds and 20 seconds resulted in full-thickness damage, involving subjacent skeletal muscle.

Conclusions This is a simple reproducible method for creating burn wounds consistent in size and depth in a rat burn model.

Keywords Animals / Burns / Rats wound healing
Correspondence: Thiam Chye Lim Division of Plastic, Aesthetic and Reconstructive Surgery, Department of Surgery, Yong Loo Lin School of Medicine, National University of Singapore, NUHS Tower Block, Level 8, 1 Kent Ridge Road, Singapore 119228, Singapore

Tel: +65-67722022

Fax: +65-67778427

E-mail: thiam_chye_lim@nuhs.edu.sg

This work is supported by the Institute of Bioengineering and Nanotechnology (Biomedical Research Council, Agency for Science, Technology and Research, Singapore) and the Defense Science Organisation, Singapore.

This work is funded by the Agency for Science, Technology and Research (Singapore) internal grant.

This work was presented in the form of a poster presentation at the Malaysia Association of Plastic, Aesthetic and Craniomaxillofacial Surgeons' Annual Scientific Meeting on April 26-28, 2013 in Ipoh, Malaysia.

No potential conflict of interest relevant to this article was reported.

\section{INTRODUCTION}

Animal experimental models are important tools for the evalua- tion of burn therapeutics. Rats are one of the most commonly used animals [1-10]. They have the cheapest cost in terms of housing, maintenance, and reproduction. Evaluation of burn

Copyright (C) 2014 The Korean Society of Plastic and Reconstructive Surgeons

This is an Open Access article distributed under the terms of the Creative Commons Attribution Non-Commercial License (http://creativecommons.org/

licenses/by-nc/3.0/) which permits unrestricted non-commercial use, distribution, and reproduction in any medium, provided the original work is properly cited. I www.e-aps.org 
wound dressings requires the creation of localized burn wounds with consistent size and depth. The technique of burn infliction is often inconsistent and poorly described in previous studies [1-7]. A review by Mitsunaga Junior et al. [10] found a large number of studies that failed to describe the burn technique and the depth of burn inflicted. Determining the depth of burn is important as it determines the choice of treatment. Full-thickness burns require early excision and skin grafting. Superficial and partial-thickness burns can be managed conservatively with wound dressings [11].

The objective of this study is to formulate a simple, cost-effective and reproducible method for creating consistent burn wounds in a rat burn model, for the evaluation of burn wound dressings.

\section{METHODS}

\section{Preparation of animals}

All procedures were approved by the Institutional Animal Care and Use Committee of our laboratory and were conducted in accordance with its established guidelines. 10 male Sprague Dawley rats (350-400 g, 6-8 weeks old) were used. Animals were obtained from our university's Comparative Medicine

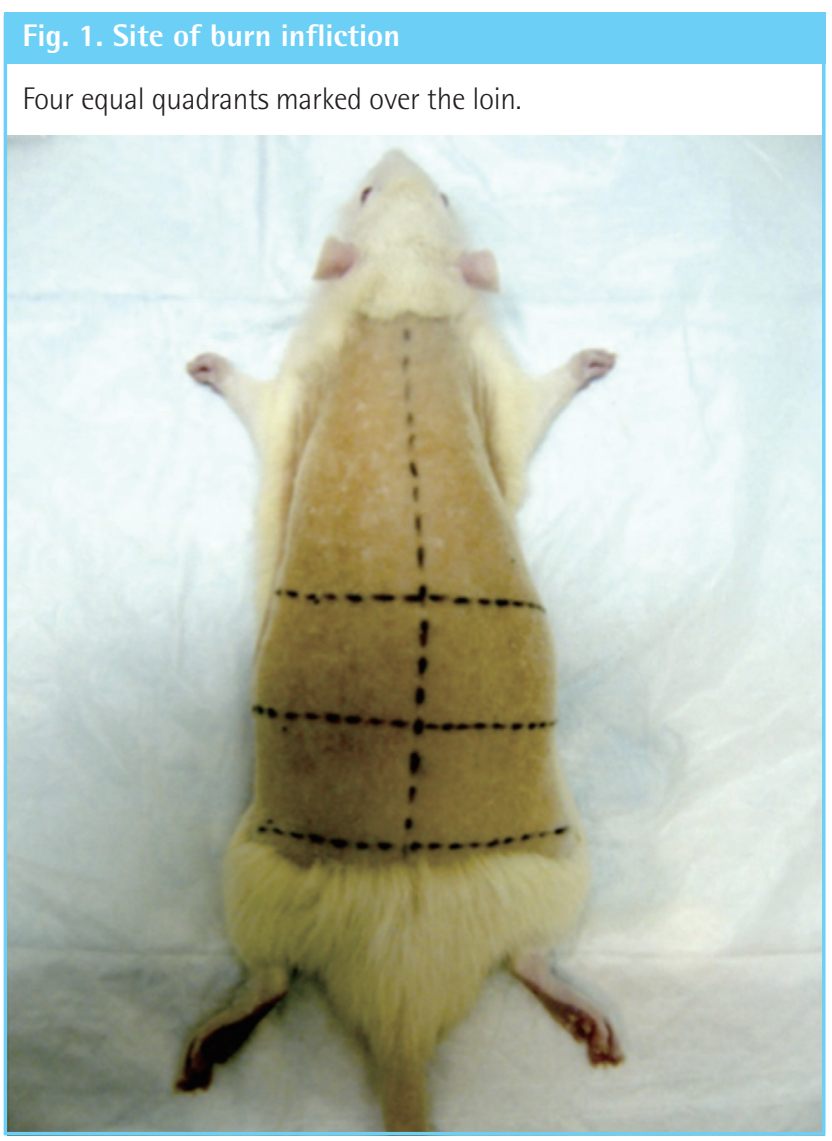

Unit. The rats were anesthetized with intra-peritoneal ketamine, Ketamine Injection $100 \mathrm{mg} / \mathrm{mL}$ (Parnell Laboratories, Auckland, New Zealand) and xylazine, Ilium-Xylazine-20 20 mg/mL (Troy Laboratories, Sydney, Australia). $7.5 \mathrm{~mL}$ of Ketamine and $5.0 \mathrm{~mL}$ of Xylazine were diluted with $7.5 \mathrm{~mL}$ of MilliQ water (Millipore, Billerica, MA, USA). A dosage of $0.2 \mathrm{~mL} / 100 \mathrm{~g}$ body-weight was used for the induction of anaesthesia.

The dorsum of the rats were shaved using a AGC2 electric shaver (Andis, Sturtevant, WI, USA) of $4 \mathrm{~cm}$ width. The shaver was held at a 45 degrees angle to the skin and a maximum of two passes across the same area was allowed, minimizing trauma to the skin. The area for burn infliction was $12 \mathrm{~cm}( \pm 2 \mathrm{~cm}) \times 8 \mathrm{~cm}$ $( \pm 2 \mathrm{~cm})$, limited to the loin. Palpation of the twelfth ribs bilaterally and drawing a horizontal line below them marked out the upper boundary. Palpation of the pelvic bone and drawing a horizontal line above it marked out the lower boundary. Palpating for and drawing a vertical line following the course of the vertebral spinous processes marked out the midline. A horizontal line bisecting the upper and lower boundaries was also drawn. These lines divided the loin into four equal areas where burns were inflicted, each quadrant accommodating a single burn wound (Fig. 1).

The skin was disinfected with 70\% isopropyl alcohol (BD, Franklin Lakes, NJ, USA). The skin was left to dry and equilibrate to the ambient temperature (standardized at $26^{\circ} \mathrm{C}$ ) for 3 minutes. The rat was placed $10 \mathrm{~cm}( \pm 5 \mathrm{~cm})$ from the flask of boiling water.

\section{Creation of burn wounds}

A $100 \mathrm{~g}$ cylindrical stainless steel rod (austenite 304, thermal conductivity $16 \mathrm{WmK}$, Metal Mania, Leicestershire, UK) of

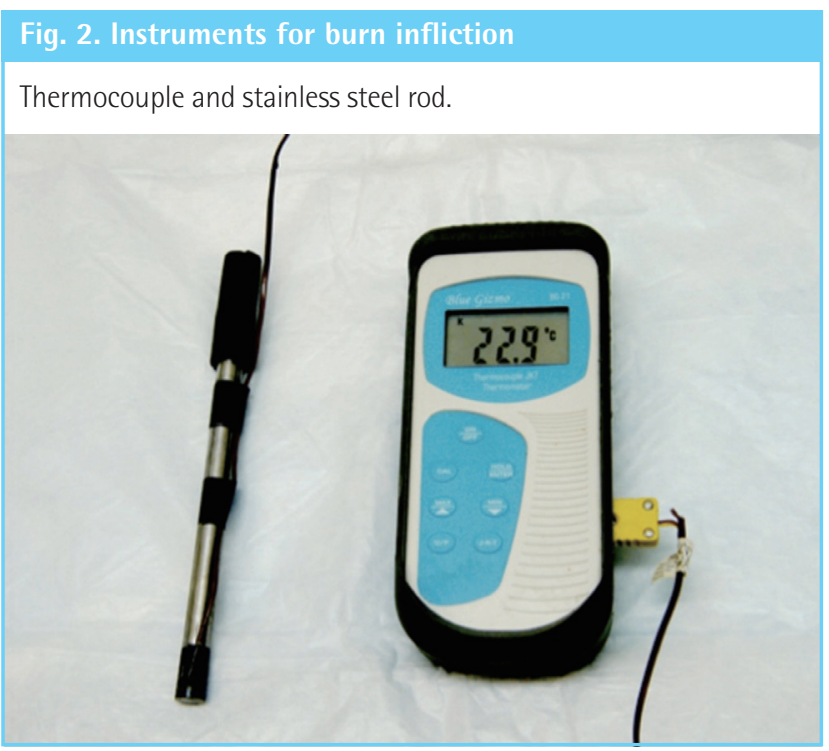




\section{Fig. 3. Positioning of the skin}

Using the thumb and index finger, the portion of skin to be burnt was pulled upwards and outwards, away from underlying viscera. The skin was pulled taut and maintained parallel to the bench. The heated rod was placed perpendicular to the skin, resting on its own weight.

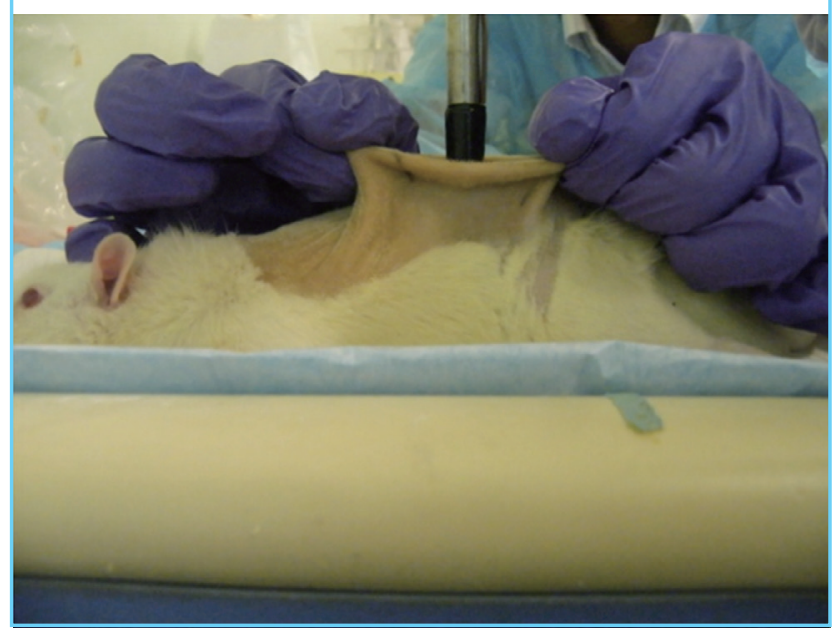

\section{Fig. 4. Grip of the rod during transfer}

Pinch the insulated handle with the thumb and middle fingers. The pulp of the index finger rests on the superior surface.

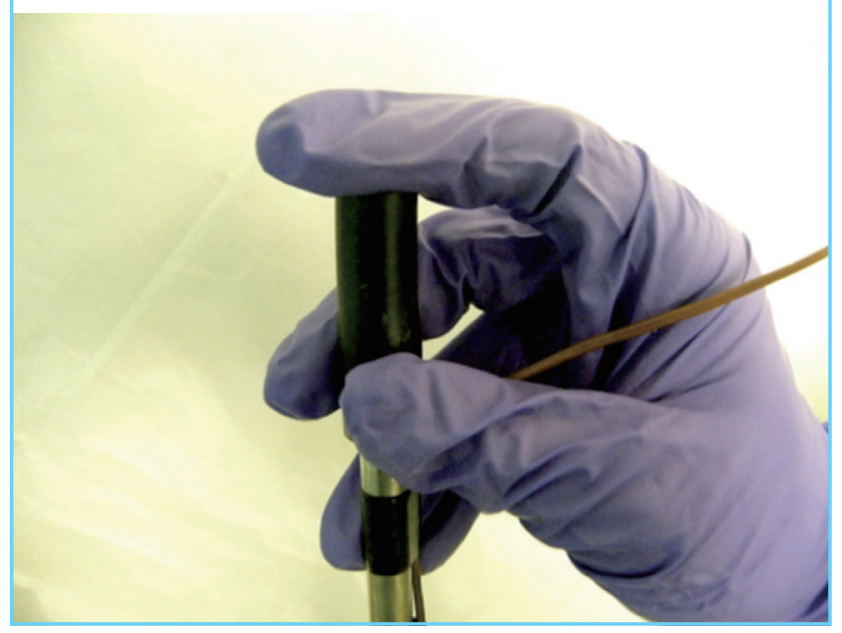

$1 \mathrm{~cm}$ diameter with an insulated rubber handle was used for the infliction of burns (Fig. 2). Temperature of the rod was monitored with a BG 21 thermocouple (Blue Gizmo, Singapore). The ends of the thermocouple wires were attached to the end of the steel rod using a polyethylene duct tape (3M, St. Paul, MN, USA). The rod was immersed in a flask of boiling water and heated up to $100^{\circ} \mathrm{C}$.

Immediately before each burn infliction, the depth of sedation was assessed by performing two consecutive toe-pinch tests on two different limbs. Using the thumb and index finger of both hands, an assistant pulls up a portion of skin from the underly-

\section{Fig. 5. Grip of the rod during burn infliction}

The thumb, index and middle fingers maintain the rod perpendicular to the skin.

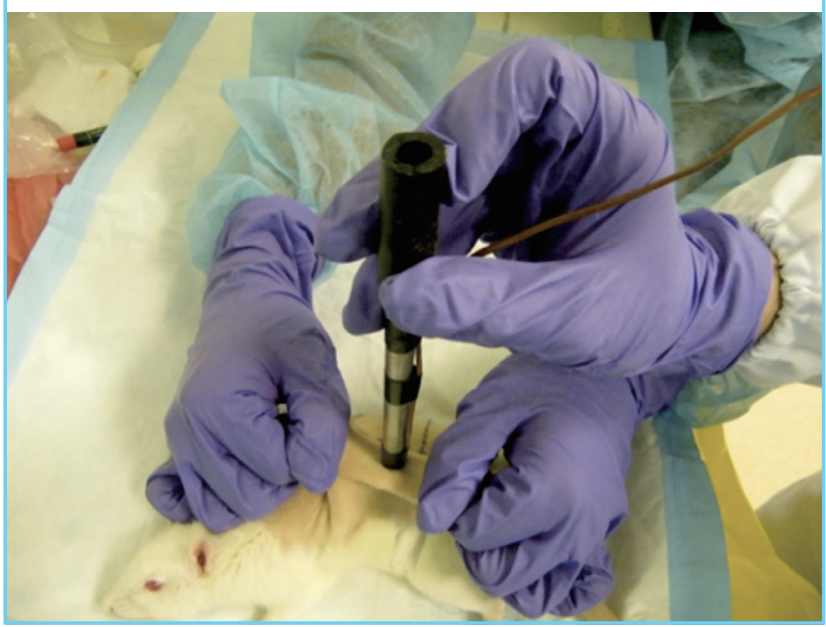

ing viscera, directing the two sides upwards and outwards. This would maintain a flat surface of skin that was held parallel to the experiment bench (Fig. 3).

The rod was lifted off the flask by pinching the insulated handle with the thumb and middle fingers. The pulp of the index finger rested on the superior surface of the rod. It provided additional support and the ability to maneuver the direction of the rod, using the thumb and middle finger as the fulcrum (Fig. 4).

Water droplets adhered onto the rod was displaced at the side of the beaker. The rod was placed perpendicular onto the skin (Fig. 3). Releasing the index finger from the superior surface of the rod and releasing the grip of the thumb and middle finger allowed the rod to rest on its own weight. The thumb, middle finger and the nail of the index finger provided minimal support, ensuring the rod remained perpendicular to the skin (Fig. 5). Transferring the rod from the boiling water to the skin took 3 seconds ( \pm 1 second), minimizing the amount of heat lost. The heated rod was held in contact with the skin for 5 seconds, 10 seconds, and 20 seconds in each of the 4 quadrants. Each quadrant accommodated a single burn wound. 3 burn wounds of different durations ( 5 seconds, 10 seconds, and 20 seconds) were created on each rat. These were randomly assigned to each of the 4 quadrants.

\section{Wound evaluation}

Wound size was measured by digitalized planimetry (Pictzar, BioVisual Technologies, Elmwood Park, NJ, USA) immediately after burn infliction. Gross morphology of the wounds in terms of color and margin was evaluated.

Immediately after the evaluation of gross morphology and 
size, the wounds were excised using scalpel and fixed in formalin. The specimens were processed in paraffin blocks and sections cut and stained with haematoxylin and eosin. A pathologist examined the sections over a multi-header microscope. The pathologist was blinded to the burn duration of every specimen. All fields of the sections were examined and the area of deepest involvement by the burn injury was concentrated on.

The condition of the epidermis, dermis, subcutaneous fat and skeletal muscle was evaluated. The deepest layer to be involved by the burn injury was recorded and the maximum depth measured with respect to the granular layer of the overlying epidermis. This was accomplished using an ocular micrometer, corroborated by ruler measurement via the ImageScope (Aperio, Technologies Inc., Vista, CA, USA) software.

\section{Euthanasia}

The rats were placed under deep anaesthesia using intra-peritoneal peritoneal ketamine, Ketamine Injection 100 mg/mL (Parnell Laboratories, Auckland, New Zealand) and xylazine, IliumXylazine-20, $20 \mathrm{mg} / \mathrm{mL}$ (Troy Laboratories, Australia). $7.5 \mathrm{~mL}$ of Ketamine and $5.0 \mathrm{~mL}$ of Xylazine were diluted with $7.5 \mathrm{~mL}$ of MilliQwater (Millipore, Billerica, MA, USA). A dosage of 0.2
$\mathrm{mL} / 100 \mathrm{~g}$ body-weight was used. The rats were subsequently euthanized by cardiac puncture.

\section{RESULTS}

\section{Macroscopic assessment}

A total of 30 wounds were created. The average wound size was $0.9957 \mathrm{~cm}^{2}$ (minimum, $0.692 \mathrm{~cm}^{2}$; maximum, $1.379 \mathrm{~cm}^{2}$ ) (standard deviation [SD], 0.1845) $(n=30)$ (Fig. 6). 10 wounds were created with a burn duration of 5 seconds. 10 wounds were created with a burn duration 10 seconds. 10 wounds were created with a burn duration of 20 seconds. There is no significant difference in size of wounds created with burn durations of 5 seconds, 10 seconds and 20 seconds respectively (type 2, two-tailed t-test: $\mathrm{P}<0.05$ ) (interquartile range, 0.287).

Burn duration of 5 seconds resulted in wounds that were circular and pale, with an indistinct margin of erythema (Fig. 7A). Wounds created with both burn duration of 10 and 20 seconds were circular with a well-defined margin, uniformly yellowbrown with a rim of erythema (Fig. 7B, C). No blistering was seen in any of the wounds.

\section{Fig. 6. Graph depicting wound size}

The average wound size was $0.9957 \mathrm{~cm}^{2}$ (minimum, $0.692 \mathrm{~cm}^{2}$; maximum, $1.379 \mathrm{~cm}^{2}$ ) (standard deviation 0.1845$)(\mathrm{n}=30)$.

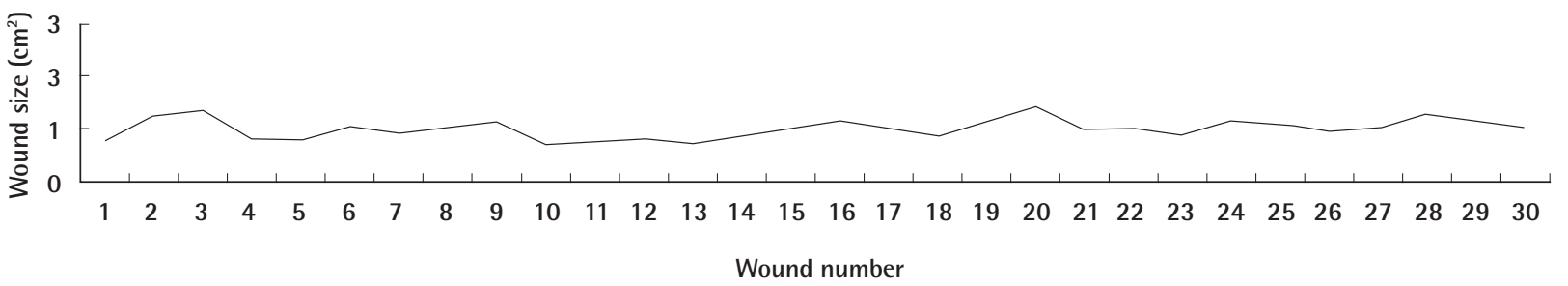

\section{Fig. 7. Gross morphology}

(A) Burn duration of 5 seconds. (B) Burn duration of 10 seconds. (C) Burn duration of 20 seconds.
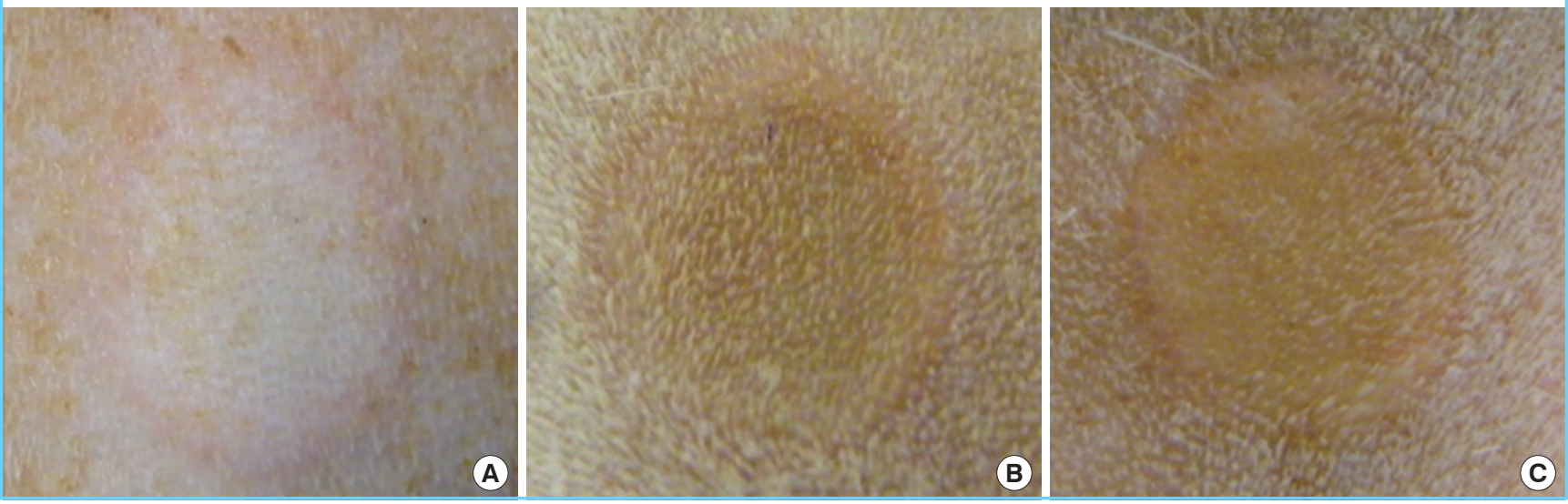


\section{Histological assessment}

The extent of tissue injury correlated with the duration of burn infliction. Burn duration of 5 seconds resulted in an average depth of $1.30 \mathrm{~mm}$ (minimum, $1.00 \mathrm{~mm}$; maximum, $1.60 \mathrm{~mm}$ ) (SD, 0.424). Burn duration of 10 seconds resulted in an average depth of $2.35 \mathrm{~mm}$ (minimum, $2.30 \mathrm{~mm}$; maximum, $2.40 \mathrm{~mm}$ ) (SD, 0.071). Burn duration of 20 seconds resulted in an average depth of $2.60 \mathrm{~mm}$ (minimum, $2.40 \mathrm{~mm}$; maximum, $2.80 \mathrm{~mm}$ ) (SD, 0.283). The depth of burn wound inflicted with a burn duration of 5 seconds is significantly smaller compared to the depth of burn wound inflicted with burn durations of $10 \mathrm{sec}-$ onds (type 2, one-tailed t-test: $\mathrm{P}=0.0373$ ) and 20 seconds (type 2, one-tailed t-test: $\mathrm{P}=0.0345$ ) respectively. There is no significant difference in depth of burn wound inflicted with a burn duration of 10 seconds and 20 seconds (type 2, one-tailed t-test: $\mathrm{P}=0.176)$. Representative histological images are shown in Fig. 8.

\section{DISCUSSION}

Rats are one of the most commonly used animals for experiments. Among other animals, they are the cheapest in terms of housing and maintenance. They are easy to handle, require little space, and have an accelerated rate of healing. We are able to conduct experiments on a large number of animals at any point in time, allowing us to yield faster results [12].

Disadvantages of using a rat model exist. There are anatomical differences between the rodent and human skin. The distribution of hair follicles and the presence of the panniculus carnosus muscle in rodent skin make it markedly different from human skin. The panniculus carnosus would cause the wounds to heal predominantly by contraction, instead of re-epithelialization $[13,14]$. Rodent skin also undergoes cyclical changes. This consists of a growing (anagen) phase and a resting (telogen) phase. Using a standardized burn technique, skin undergoing the anagenic phase might result in a more superficial burn, while skin

\section{Fig. 8. Wound histology}

(A) Burn duration of 5 seconds. The skin shows attenuated epidermis with coagulative damage to the full thickness of the dermis and the subcutaneous fat, with sparing of the subjacent skeletal muscle. Maximum depth of tissue damage: $1.6 \mathrm{~mm}$. Inset: higher magnification view of the dermal collagen and adipocytes showing thermal damage (H\&E; main, $\times 20$; inset, $\times 200)$. (B) Burn duration of 10 seconds. The skin shows attenuated epidermis with thermal coagulative damage to the full thickness of the dermis with involvement of the subcutaneous fat and the subjacent skeletal muscle. Maximum depth of tissue damage: $2.3 \mathrm{~mm}$. Inset: higher magnification view of the skeletal muscle showing thermal damage manifesting as vacuolar change $(H \& E ;$ main, $\times 20$; inset, $\times 200)$. (C) Burn duration of 20 seconds. The skin shows attenuated epidermis with area of denudation. There is thermal coagulative damage to the full thickness of the dermis with involvement of the subcutaneous fat and the subjacent skeletal muscle. Maximum depth of tissue damage: $2.4 \mathrm{~mm}$. Inset: higher magnification view of the skeletal muscle showing thermal damage manifesting as vacuolar change (upper portion), contrasting with the spared deeper muscle fibres (lower portion) (H\&E; main, $X$ 20 ; inset, $\times 200$ )

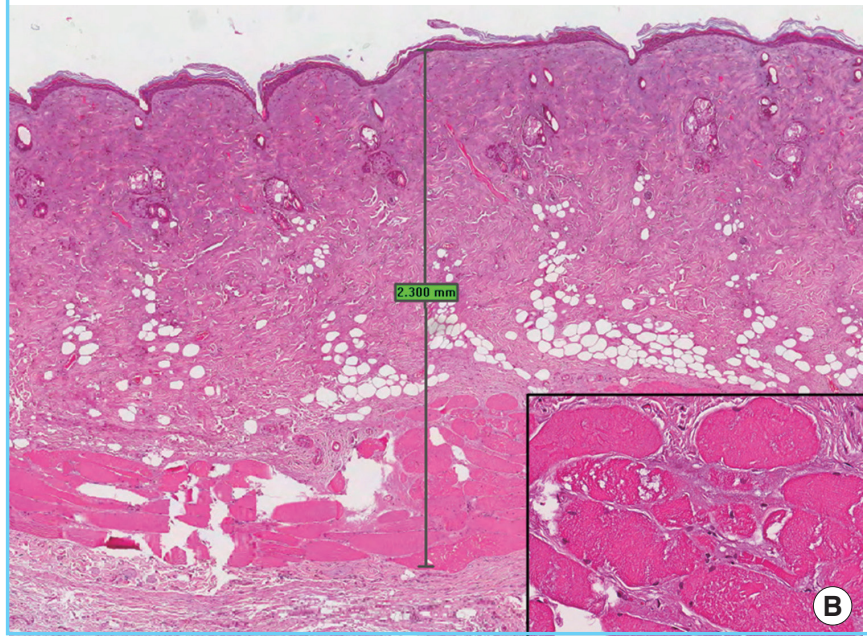

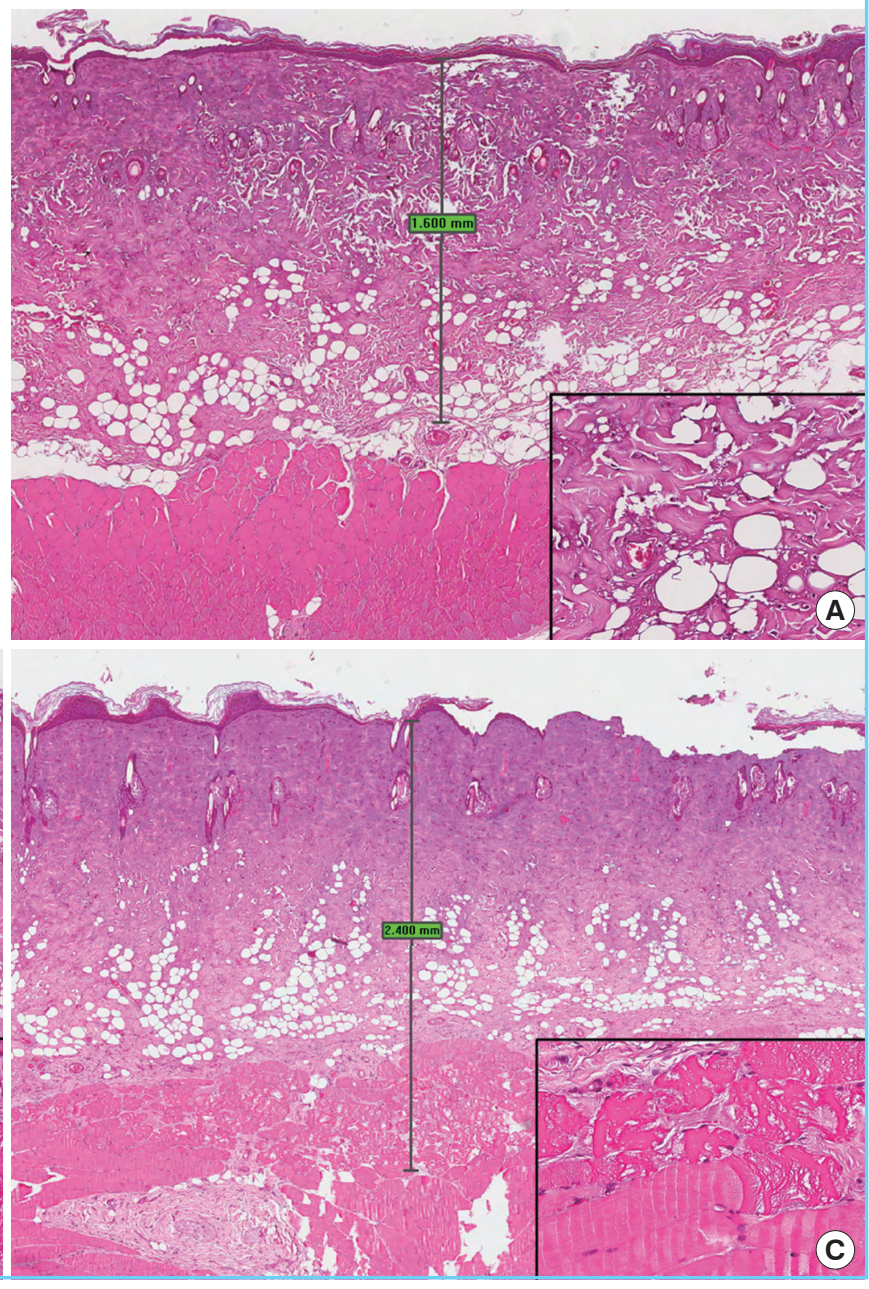


undergoing the telogenic phase might be injured to a deeper layer [15]. It is important to take into account these differences when conducting wound healing experiments in rats. Recognizing the distinct stages of hair cycling require histological micrographs [16], which is impractical. There are other methods to ensure the rats are in the same stage to avoid variability in the depth of burn created. The highly standardized C57BL/6NCr1BR (C57BL/6) model of depilation-induced hair follicle cycling [17] involves applying a wax/rosin mixture on the dorsal skin of a mouse. Removing the wax/rosin mixture removes all the hair shafts and induces the anagen development over the entire depilated back of the mouse. Thereafter, the consecutive stages of catagen and telogen are entered in a homogeneous manner [16]. A simpler alternative is to choose younger rats with highly synchronized hair follicle cycle. The cycle becomes more variable as the rat ages [18].

Wounds situated at different areas of the body heal with different extent of contraction [19]. The area for burn creation in this study was therefore limited to the loin. The method described for marking out the loin was adapted from a study done by Mohd Zohdi et al. [7] Limiting the wounds to the loin wound also prevent the rat from reaching the wounds.

There are many methods for creating burn wounds in rodents. The use of heated instruments is one of the most widely used methods [10]. Of the heated instruments, metal rods heated with boiling water is one of the most commonly used methods [1,3-5,9]. An ideal experimental protocol would achieve burn wounds that are consistent in size and depth.

\section{Depth of burn}

Before burn infliction, the skin of the rats will be sterilized using alcohol swabs. We recommend leaving the skin to dry and equilibrate with the ambient temperature for 3 minutes after cleaning. This is an important step to standardize the temperature of the skin before burn infliction, which is often neglected in previous studies [1-9].

Rods used in similar studies were usually made of brass $[1,4,6]$ or aluminum $[7,9]$. A number of studies have failed to state the material of rod that was used $[2,3,5]$. A stainless steel rod was used in this study. Factors that determine the choice of material used include its thermal conductivity and the ability to resist rust and corrosion. Stainless steel with a low thermal conductivity of $16 \mathrm{WmK}$, compared to aluminum or brass with a high thermal conductivity of $225 \mathrm{WmK}$ and $109 \mathrm{WmK}$ respectively, is preferred [20]. This prevents excessive heat loss during the procedure of burn infliction. The material of rod influences how rapidly heat is conducted from the rod to the skin, and subsequently the depth of burn. Metal rods with high thermal conductivity would cause a deeper level of burn compared to metal rods with lower thermal conductivity, when exposed to the skin for the same duration. Using a metal rod with low thermal conductivity would allow greater control over the depth of burn infliction.

A review of previous studies shows that temperature of the heated rod varied from $70^{\circ} \mathrm{C}$ to $100^{\circ} \mathrm{C}$, and duration of burns varied from touch to $45 \mathrm{~s}[1-5,9,10]$. The rod was heated to $100^{\circ} \mathrm{C}$ in this study. A convenient method for heating up the rod was to immerse it in a flask of boiling water, allowing the temperature to equilibrate. Other methods include exposing the rod to open flame [2]. This is an inconvenient method. It requires constant monitoring of the temperature of the rod to prevent it from overheating. It is also important to position the flask of boiling water as close as possible to the rat while allowing for a comfortable working area. This is to prevent excessive heat loss during transfer of the rod from the flask to the skin.

The temperature of the boiling water can be measured conveniently using a thermometer. Methods for monitoring the temperature of the heated rod vary between studies. An example would be the use of a digitalized multimeter [5]. In this study, a thermocouple was used. Most studies have failed to directly monitor the temperature of the rod [1-4]. Only temperature of the water was monitored using a thermometer $[7,9]$. The rod was assumed to have equilibrated with the temperature of the water after a few minutes. It is crucial to ensure that equilibration has indeed taken place by directly measuring the temperature of the rod.

During burn infliction, the heated rod should be allowed to rest on its own weight $[5,9]$. We find this the most convenient and accurate method for standardizing the pressure exerted by the rod onto the skin. We do not recommend pressing the rod onto the skin as described by certain studies $[1,2]$. This would result in a different amount of pressure exerted with each burn. The weight of the rod is the main determinant of the pressure exerted. In our study, we used a rod weighing $100 \mathrm{~g}$. Weight of the rod varied in previous studies, varying from 30 to $51 \mathrm{~g}[5,9]$.

The duration of burn determines the depth of burn inflicted. The extent of tissue necrosis increases with increasing contact duration between the heated rod and skin. A 5 second burn resulted in a full-thickness burn with involvement of the entire dermis and subcutaneous tissue, with sparing of the skeletal muscle layers. Contact duration of 10 seconds or greater resulted in the involvement of the entire dermis, subcutaneous tissue, and a portion of the subjacent skeletal muscle.

The temperature of the heated rod, duration of burn, and weight of rod can be modified accordingly to achieve the desired depth of burn (Table 1). 


\section{Fig. 9. Negative example}

(A) An oval-shaped burn wound. The result of a rod that had slipped during burn infliction. (B) Enlarged burn wound with irregular margins. The result of inadequate anaesthesia causing muscular contractions and undesired infliction of burn to the surrounding skin. Irregular margins could also be caused by retained water droplets on the rod. (C) Non-uniform burn wound, with greater amount of pressure exerted on the right. The result of not maintaining the rod perpendicular to the skin throughout the duration of the burn. Not lifting the skin away from the underlying viscera would also cause non-uniform burns.
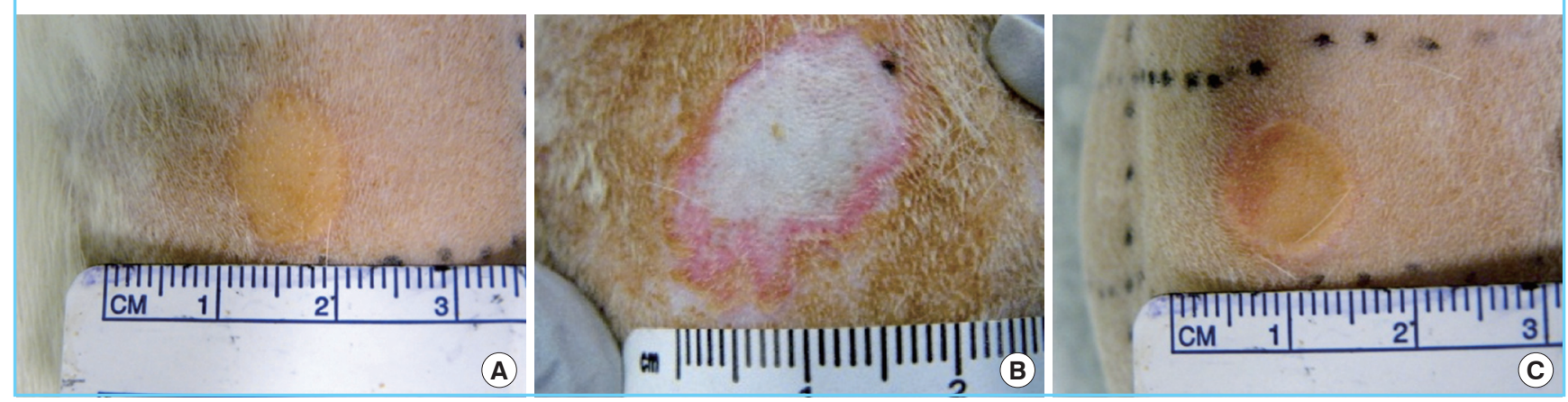

\section{Table 1. Factors affecting depth of burn}

1. Temperature of skin

2. Material of rod

3. Temperature of rod

4. Weight of rod

5. Duration of burn

\section{Uniformity of burn}

Metal rods resistant to rust and corrosion are suitable candidates. Rust and corrosion could form after repeated experiments, resulting in uneven surfaces on the metal rod. A smooth surface of the rod that comes in contact with the skin is necessary for a uniform burn wound.

If the location of burn that is closer to the midline is desired, the rat could be positioned in the prone position. If the location of burn that is further from the midline is desired, the rat could be placed in the lateral position. This facilitates the subsequent maneuver of adjusting the skin parallel to the bench.

The area of skin to be burnt has to be pulled taut, lifted upwards and outwards away from the underlying intra-abdominal organs, and maintained parallel to the bench. These steps are crucial in obtaining uniform burns. Skin pulled away from the underlying viscera will prevent non-uniform burns due to uneven contours of the intra-abdominal organs. A flat surface parallel to the experimental bench prevents slippage of the rod, which would cause irregularly shaped burns (Fig. 9A). This is one of the most crucial steps to attain uniform burn wounds, which previous studies have failed to describe $[1-7,9,10]$.

Performing two consecutive toe-pinch tests on any two limbs immediately before inflicting burns would ensure an adequately anaesthetized rat. This prevents any involuntary muscular contractions during burn infliction. Involuntary muscular contractions at the burn site would cause the skin around the periphery

\section{Table 2. Factors contributing to uniform burn wounds}

1. Surface of rod

2. Position of rat

3. Position of skin

4. Depth of sedation

5. Presence of water droplets on the rod

6. Position of rod

of rod to come in contact with it. This would result in irregular burn margins, wounds larger than desired, and an uneven depth of burn (Fig. 9B).

After lifting the rod from the water, water droplets adhered to the rod would cause irregular burn margins. Displacing any retained water droplets at the side of the flask would prevent this.

Once the rod comes in contact with the skin, the thumb, middle finger and curled index finger have to provide support to keep the rod perpendicular to the skin. In addition, an assistant could be positioned to look at the rod front-on, ensuring that it remains perpendicular to the skin throughout the duration of burn. Having the rod perpendicular to the skin would ensure uniform distribution of pressure from the weight of the rod (Fig. 9C). Previous studies often mentioned the need for the rod to be perpendicular to the skin, but do not describe the method for doing so $[1-7,9,10]$. The factors affecting the uniformity of burn wounds are summarized in Table 2 .

We have presented a simple and effective method for creating consistent burn wounds that is easily reproducible. This is a cost-effective model for evaluating wound dressings and other topical therapeutics for the treatment of burn wounds.

\section{REFERENCES}

1. Pessolato AG, Martins Ddos S, Ambrosio CE, et al. Propolis 
and amnion reepithelialise second-degree burns in rats. Burns 2011;37:1192-201.

2. Gurung S, Skalko-Basnet N. Wound healing properties of Carica papaya latex: in vivo evaluation in mice burn model. J Ethnopharmacol 2009; 121:338-41.

3. Priya KS, Gnanamani A, Radhakrishnan N, et al. Healing potential of Datura alba on burn wounds in albino rats. J Ethnopharmacol 2002;83:193-9.

4. Eloy R, Cornillac AM. Wound healing of burns in rats treated with a new amino acid copolymer membrane. Burns 1992; 18:405-11.

5. Upadhyay NK, Kumar R, Mandotra SK, et al. Safety and healing efficacy of Sea buckthorn (Hippophae rhamnoides L.) seed oil on burn wounds in rats. Food Chem Toxicol 2009; 47:1146-53.

6. Meyer TN, Silva AL. A standard burn model using rats. Acta Cir Bras 1999;14. http://dx.doi.org/10.1590/S0102-8650 1999000400009.

7. Mohd Zohdi R, Abu Bakar Zakaria Z, Yusof N, et al. Gelam (Melaleuca spp.) Honey-Based Hydrogel as Burn Wound Dressing. Evid Based Complement Alternat Med 2012; 2012:843025.

8. Campelo AP, Campelo MW, Britto GA, et al. An optimized animal model for partial and total skin thickness burns studies. Acta Cir Bras 2011;26 Suppl 1:38-42.

9. Tavares Pereira Ddos S, Lima-Ribeiro MH, de Pontes-Filho NT, et al. Development of animal model for studying deep second-degree thermal burns. J Biomed Biotechnol 2012; 2012:460841.

10. Mitsunaga Junior JK, Gragnani A, Ramos ML, et al. Rat an experimental model for burns: a systematic review. Acta Cir Bras 2012;27:417-23.

11. Benson A, Dickson WA, Boyce DE. ABC of wound healing: burns. BMJ 2006;332:649-52.

12. Galiano RD, Michaels Jt, Dobryansky M, et al. Quantitative and reproducible murine model of excisional wound healing. Wound Repair Regen 2004;12:485-92.

13. Montandon D, D'Andiran G, Gabbiani G. The mechanism of wound contraction and epithelialization: clinical and experimental studies. Clin Plast Surg 1977;4:325-46.

14. Aksoy MH, Vargel I, Canter IH, et al. A new experimental hypertrophic scar model in guinea pigs. Aesthetic Plast Surg 2002;26:388-96.

15. Zawacki BE, Jones RJ. Standard depth burns in the rat: the importance of the hair growth cycle. Br J Plast Surg 1967; 20:347-54.

16. Muller-Rover S, Handjiski B, van der Veen C, et al. A comprehensive guide for the accurate classification of murine hair follicles in distinct hair cycle stages. J Invest Dermatol 2001;117:3-15.

17. Chase HB. Growth of the hair. Physiol Rev 1954;34:113-26.

18. Plikus MV, Mayer JA, de la Cruz D, et al. Cyclic dermal BMP signalling regulates stem cell activation during hair regeneration. Nature 2008;451:340-4.

19. Hinrichsen N, Birk-Sorensen L, Gottrup F, et al. Wound contraction in an experimental porcine model. Scand J Plast Reconstr Surg Hand Surg 1998;32:243-8.

20. Goldratt E, Greenfield AJ. New method for measuring the thermal conductivity. Rev Sci Instrum 1978;49:1531. 